\title{
Analisis Control Flow Complexity Untuk Komparasi Kompleksitas Proses Bisnis Penerimaan Mahasiswa Baru Universitas Nahdlatul Ulama Blitar Berbasis Petri Net Modelling Language
}

\author{
Ahmad Yunus ${ }^{1, *}$, Abd. Charis Fauzan ${ }^{2}$, Achmad Nuuril Faizin ${ }^{3}$, Kharisma Sabbihatul \\ Mustaghfaroh $^{4}$, Afrida Danar Pratama ${ }^{5}$ \\ Program Studi Ilmu Komputer, Universitas Nahdlatul Ulama Blitar, Indonesia \\ ${ }_{1}$ iquerza@gmail.com; ${ }^{2}$ abdcharis@ @unublitar.ac.id; ${ }^{3}$ nuuril.faizinachmad@gmail.com; ${ }^{4}$ kharisstyles@ gmail.com; \\ 5danar05021997@gmail.com \\ * corresponding author
}

\section{ARTIKEL INFO}

\section{Article history}

Diterima: 23 Oktober 2019

Direvisi: 15 November 2019

Diterbitkan: 30 Desember 2019

Keywords

Control flow complexity

Kompleksitas proses bisnis

PNML

\section{ABSTRAK}

Tujuan dari penelitian ini adalah menganalisis Control Flow Complexity (CFC) untuk menguji kompleksitas dua model proses bisnis berbasis Petri Net Modelling Language (PNML). Dengan data yang digunakan adalah model proses bisnis Penerimaan Mahasiswa Baru Universitas Nahdlatul Ulama Blitar jalur daring (online) dan luring (offline). Peneliti memodelkan proses bisnis Penerimaan Mahasiswa Baru Universitas Nahdlatul Ulama Blitar menggunakan metode PNML, CFC dan komparasi. Hasil penelitian ini merujuk ke hasil komparasi perbandingan antara kompleksitas jalur daring dan luring. Semakin besar suatu model proses bisnis, maka kompleksitasnya semakin besar.

\section{PENDAHULUAN}

Model proses bisnis adalah serangkaian kegitatan yang berhasil di koordinasikan dalam suatu organisasi dan lingkungan teknis [1]. Dalam manajemen proses bisnis, kompleksitas model proses bisnis dihasilkan dari banyak fungsi dan proses yang saling berhubungan dimana semuanya sangat kompleks, bahkan beberapa lebih kompleks dari yang lainnya sesuai dengan pengukuran struktur kompleksitas proses model yang telah diterapkan dalam sistem berbasis layanan Web [2]. Kompleksitas merupakan indikator hubungan dalam suatu proyek atau program yang mempengaruhi bagaimana hubungan ini akan dikelola dan keahlian apa yang dibutuhkan untuk mengelolanya. Banyak organisasi sudah menggunakan teknologi manajemen proses bisnis. Pada penelitian sebelumnya, skalabilitas model bisnis proses telah dilakukan pengukuran dengan membandingkan kesamaan dari beberapa proses bisnis dan skala mereka. Metode pengukuran kesamaan yang diusulkan didasarkan pada struktural dan perilaku menggunakan Jaccard koefisien, sedangkan jumlah elemen model proses bisnis dan kontrol kompleksitas aliran digunakan untuk mengukur skalanya. Lalu, nilai skalanya antara 0 - 1 dan kesamaan model proses bisnis dihitung dengan rumus yang ditentukan. Hasilnya adalah nilai skalabilitas, di mana semakin besar nilai skalabilitas, maka potensi pertumbuhan bisnis prosesnya juga lebih besar [3].

Model proses bisnis semestinya mudah dipahami dan mudah untuk di-maintain. Salah satu penyebab model proses bisnis menjadi tidak mudah dipahami adalah tingginya kompleksitas pada model proses bisnis tersebut. Kompleksitas yang tinggi merupakan kelemahan model proses bisnis yang rawan menyebabkan kesalahpahaman (bad understandability), cacat, serta kesalahan penafsiran proses bisnis sehingga biaya untuk 
mengembangkan dan menguji proses bisnis menjadi lebih mahal dan membutuhkan tambahan waktu. Langkah awal untuk mereduksi kompleksitas model proses bisnis adalah mengenali keberadaan elemen kompleksitas kemudian mengukur besarnya kompleksitas. Cardoso [4] mendefinisikan kompleksitas proses bisnis sebagai derajat tingkat kesulitan proses bisnis untuk dianalisa, dipahami dan dijelaskan. Kemudian mengusulkan Control Flow Complexity (CFC) sebagai matrik pengukuran derajat kompleksitas proses bisnis. Dalam hal ini proses bisnis telah dimodelkan dalam notasi pemodelan tertentu. Misalnya, BPMN (Business Process Modelling Notation), PNML (Petri Net Modelling Language) atau pemodelan lainnya. Cardoso memilih memakai BPNM untuk mengukur kompleksitas model, maka disini peneliti akan mengukur kompleksitas model menggunakan pemodelan yang lain yaitu Petri Net Modelling Language (PNML).

Berdasarkan uraian, peneliti menghitung kompleksitas menggunakan CFC dengan studi kasus model proses bisnis Penerimaan Mahasiswa Baru (PMB) di Universitas Nahdlatul Ulama Blitar. Dimana Universitas Nahdlatul Ulama Blitar telah menerapkan dua jalur PMB yaitu jalur PMB luiar jaringan (luring) dengan langsung menghubungi admin dan jalur PMB dalam jaringan (daring) dengan langsung tersambung ke internet. Maka peneliti menggunakan dua model proses bisnis yang mewakili kondisi tersebut untuk membandingkan kompleksitas proses bisnisnya. Penelitian ini berfokus pada analisis kompleksitas model proses bisnis. Setiap proses bisnis dimodelkan menggunakan Petri Net. Petri Net digunakan sebagai model proses bisnis karena notasi modelnya yang sederhana sehingga dapat dianalisis secara matematis. Control Flow Complexity digunakan untuk menghitung kompleksitas. Lalu, nilai kompleksitas dan kesamaan model proses bisnis dihitung dengan rumus yang ditentukan. Pengukuran CFC didasarkan pada hipotesis bahwa perilaku control flow pada proses bisnis dipengaruhi oleh split (perpecahan) dan join (gabungan). Namun, dalam mengukur CFC, perumusan formula untuk kompleksitas dititikberatkan pada pengaruh split yang ada pada model proses bisnis. Split yang umum dijumpai pada model proses bisnis adalah AND-split, XOR-split dan OR-split [5].

\section{METODE}

\section{Petri Net Modelling Language (PNML)}

Pada saat mendeskripsikan suatu prosedur atau proses terasa sulit jika hanya menggunakan kata-kata atau algoritma saja. Terkadang juga diperlukan keteranganketerangan atau aturan yang seringkali sulit dimengerti. Setiap orang memiliki cara-cara tersendiri untuk menggambarkan algoritma tersebut. Salah satu yang digunakan untuk memodelkan suatu prosedur adalah Petri Net. Petri Net Modelling Language (PNML) adalah pemodelan proses bisnis yang bertujuan untuk menganalisis berbagai model dalam proses bisnis [6]. Petri Net atau yang disebut Place/Transition Net merupakan salah satu dari pemodelan untuk mendeskripsikan konkurensi dan sinkronisasi dalam sistem terdistribusi. Petri net hampir sama dengan State Transition Diagram yang menggambarkan perilaku sistem secara real-time dan hubungannya dengan user, namun lebih kuat secara matematis dan notasinya. Secara umum Petri Net terdiri atas 3 bagian [7]:

- Places (lingkaran) $\rightarrow$ Merepresentasikan state/kondisi dari sistem.

- Transitions (persegi panjang) $\rightarrow$ Merupakan event/kejadian atau action/aksi yang menyebabkan perubahan kondisi state.

- Arcs (anak panah) $\rightarrow$ Menghubungan place dengan transition atau transition dengan place.

Intinya Petri Net menggambarkan bagaimana perubahan-perubahan suatu state, yang dapat ditunjukan oleh token (titik hitam) dengan cara : 
- Perpindahan token dari place ke place dilakukan oleh transition dengan menembakkannya (firing).

- Sebuah Transition dapat melakukan firing atau dikatakan enable apabila terdapat token yang cukup pada input place.

- Setelah di-firing, token akan berpindah dari input place (state yang lama) ke output place, sehingga menunjukan state baru.

Disini peneliti membuat desain PNML Penerimaan Mahasiswa baru dengan WoPed menggunakan percabangan Xor dan And. WoPeD sendiri adalah alat untuk pemodelan dan analisis model proses sebagai Petri Net.

\section{Control Flow Complexity (CFC)}

Proses kompleksitas proses bisnis di definisikan sebagai tingkat kesulitan proses bisnis untuk dianalisis, dipahami, atau dijelaskan. Matrik yang digunakan untuk menganalisis kompleksitas proses bisnis adalah Control Flow Complexity (CFC) [3]. Pengukuran CFC dilakukan dengan menjumlahkan semua percabangan terpisah seperti rumus dibawah :

$$
C F C(x)=\sum C F C_{X O R-s p l i t}(x)+\sum C F C_{O R-s p l i t}(x)+\sum C F C_{A N D-s p l i t}(x)
$$

$$
\begin{aligned}
\text { dimana }: & \sum C F C_{X O R-s p l i t}(x)=\text { jumlah percabangan }(\mathrm{x}) \\
& \sum C F C_{O R-\text { split }}(x)=2^{\text {(jumlah percabangan(x)-1) }} \\
& \sum C F C_{A N D \text {-split }}(x)=1
\end{aligned}
$$

Dengan ketentuan, semakin besar nilai CFC berarti keseluruhan kompleksitas struktural juga lebih tinggi.

\section{Komparasi}

Komparasi dalam hal ini dimaksudkan untuk membandingkan data-data yang ditarik ke dalam kesimpulan atau pendapat baru agar menemukan persamaan dari dua kelompok data atau lebih. Dengan menggunakan metode komparasi ini peneliti bermaksud untuk menarik sebuah konklusi dengan cara mengukur kompleksitas dari dua model proses bisnis Penerimaan Mahasiswa Baru (PMB) di Universitas Nadlatul Ulama Blitar menggunakan hasil dari rumus CFC.

\section{PEMBAHASAN}

\section{Memodelkan Proses Bisnis Luring \& Daring dengan PNML}

Langkah pertama yang dilakukan yaitu memodelkan proses bisnis menjadi bentuk Petri Net Modelling Language. Disini peneliti membuat desain PNML Penerimaan Mahasiswa baru dengan bantuan WoPed menggunakan percabangan yang dibutuhkan yaitu Xor-split dan And-split. WoPeD sendiri adalah alat untuk pemodelan dan analisis model proses bisnis. Proses bisnis jalur luring peneliti ibaratkan dengan jalur A dan proses bisnis B untuk jalur daring. Hasilnya seperti Gambar 1. Berdasarkan Gambar 1, dapat di deskripsikan sebagai berikut :

1. Calon mahasiswa mengambil dan membeli formulir pendaftaran diruang admin Universitas Nahdlatul Ulama Blitar pada waktu pendaftaran yang telah ditentukan.

2. Selanjutnya, calon mahasiswa mengisikan data pada formulir pendaftaran sesuai dengan tata cara yang telah ditentukan oleh pihak kampus.

3. Calon mahasiswa menyerahkan formulir yang sudah diisi serta melampirkan berkas-berkas pendaftaran dan diserahkan pada admin Universitas Nahdlatul Ulama 
Blitar untuk dikelompokkan berdasarkan satu dari 10 program studi yang telah dipilih oleh calon mahasiswa.

4. Calon mahasiswa memilih jalur :

- Jalur Beasiswa

- Jalur Prestasi

- Jalur Reguler

5. Calon mahasiswa mempersiapkan berkas pendukung beasiswa/prestasi dan di,kumpulkan ke bagian admin.

6. Admin mengecek berkas-berkas yang telah dikumpulkan oleh calon mahasiswa.

7. Calon mahasiswa membayar biaya ujian tes tulis dan tes wawancara.

8. Calon mahasiswa melakukan ujian tes tulis dan tes wawancara ditempat yang telah ditentukan panitia PMB.

9. Calon mahasiswa menunggu pengumuman hasil ujian tes tulis dan tes wawancara dikampus.

10. Calon mahasiswa membayar biaya pendaftaran ulang jika sudah dinyatakan lulus ujian dan diterima sebagai mahasiswa Universitas Nahdlatul Ulama Blitar.
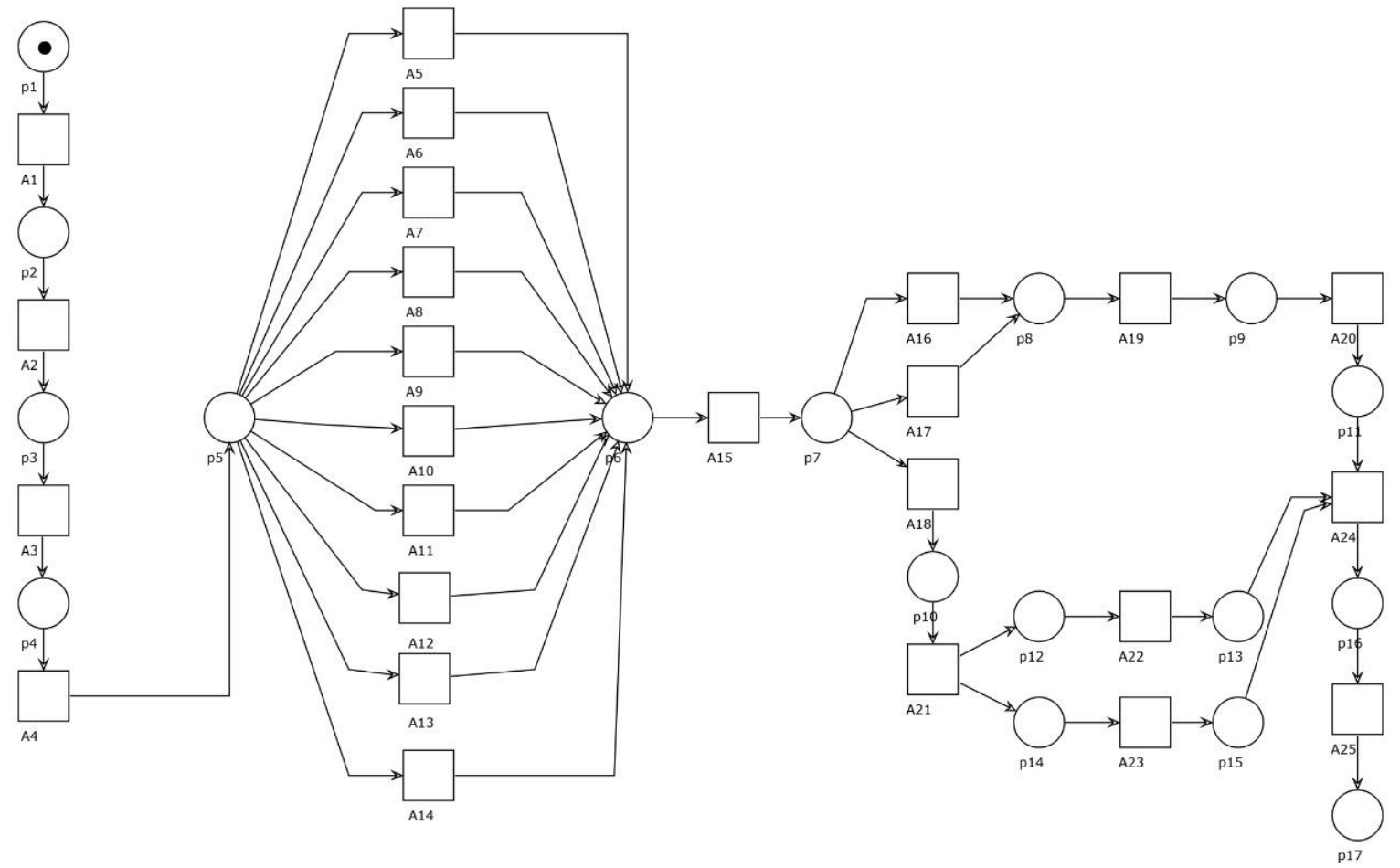

Gambar 1. Proses Bisnis PMB luring dengan PNML

\section{KETERANGAN:}

A1 : Camaba membeli formulir pendaftaran

A2 : Pengisian formulir oleh camaba

A3 : Pengembalian formulir sekaligus berkas pendaftaran oleh camaba ke bagian admin

A4 : Pengelompokan formulir oleh admin sesuai prodi yang dipilih

A5 - A14 : ( PGSD, Pend. Olahraga, Pend. Bahasa Indonesia, Pend. Bahasa Inggris, Fisika, Matematika,

Ilmu Komputer, Teknik Sipil, Teknik Mesin, Peternakan )

A15 : Pengecekan dokumen ole admin

A16 : Jalur Beasiswa

A17 : Jalur Prestasi

A18 : Jalur Reguler

A19 : Camaba menyiapkan berkas pendukung beasiswa/prestasi 
A20 : Pengecekan berkas pendukung oleh admin

A21 : Camaba membayar biaya ujian tes tulis dan wawancara

A22 : Camaba melaksanakan tes tulis

A23 : Camaba melaksanakan tes wawancara

A24 : Pengumuman hasil seleksi

A25 : Camaba melakukan pendaftaran ulang jika lolos seleksi

p5 : Xor join

p6 : Xor split

p7 : Xor join

p8 : Xor split

p10 : Xor split

p12: And

p13: And

p14: And

$\mathrm{p} 15:$ And

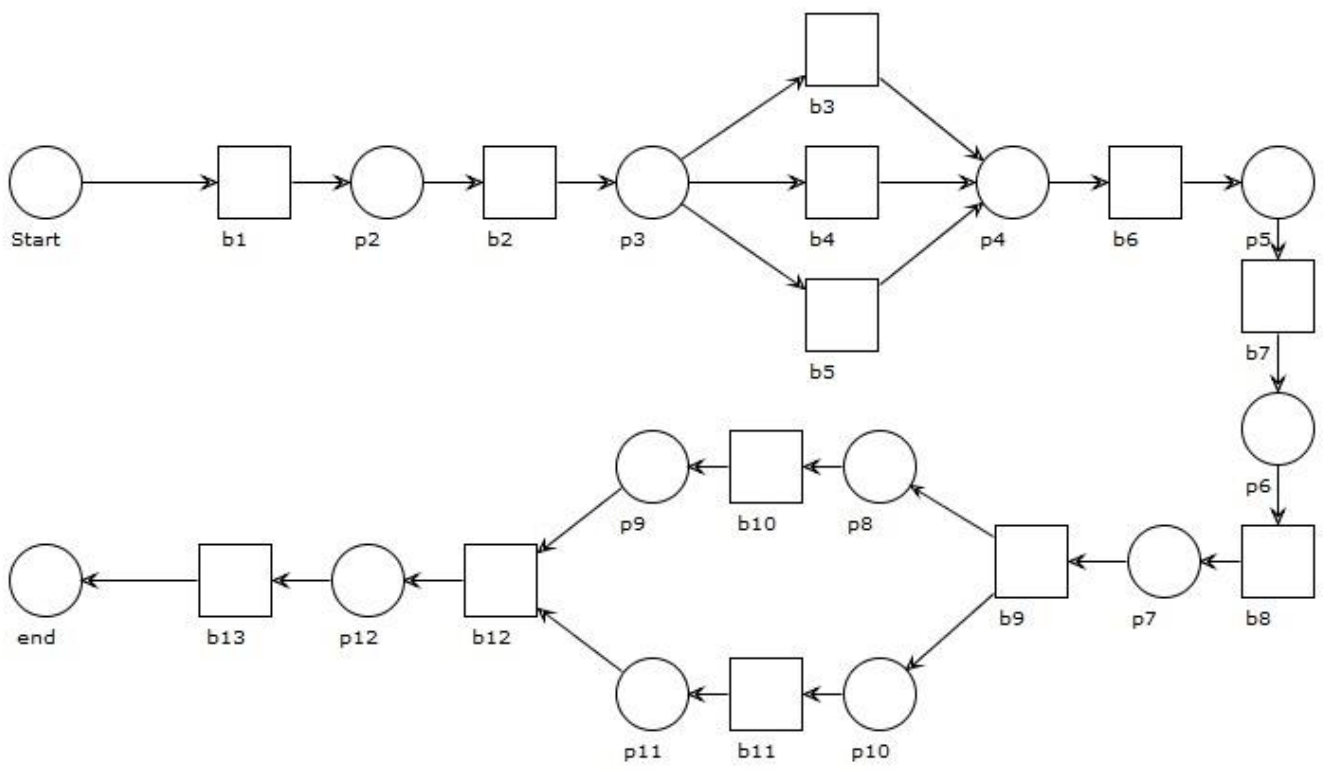

Gambar 2. Proses Bisnis PMB daring dengan PNML

\section{KETERANGAN :}

b1 : Camaba melakukan pendaftaran online

b2 : Camaba mengisi form pendaftaran online

b3 : Jalur Reguler

b4 : Jalur Beasiswa

b5 : Jalur Prestasi non Akademik

b6 : Camaba mengecek form yang telah diisi

b7 : Camaba mencetak bukti pendaftaran

b8 : Camaba membayar biaya pendaftaran ke bank

b9 : Menyerahkan berkas pendaftaran ke bagian admin

b10: Tes tulis

b11 : Tes wawancara

b12 : Pengumuman hasil seleksi

b13 : Daftar ulang

p3 : Xor join

p4 : Xor split

p8 : And

p9 : And 
p10 : And

Berdasarkan Gambar 2, dapat di deskripsikan sebagai berikut:

1. Calon mahasiswa melakukan pendaftaran online pada halaman web pmb.unublitar.ac.id. Sebelumnya, calon mahasiswa baru harus terdaftar dan telah melakukan aktivasi untuk masuk ke sistem PMB Oline.

2. Calon mahasiswa mengisi form pendaftaran online dengan memilih 1 dari 3 jalur :

- Jalur Mandiri

- Jalur Beasiswa

- Jalur Prestasi Non-Akademik

3. Calon mahasiswa mengecek kembali form yang tadi diisikan agar tidak terjadi kesalahan pada data calon mahasiswa.

4. Calon mahasiswa mencetak bukti pendaftaran sebagai syarat ujian tes tulis dan tes wawancara yang didalamnya tercantum nomor ujian.

5. Calon mahasiswa membayar biaya pendaftaran sebesar Rp.200.000 untuk semua jalur dan ditansfer melalui bank BRI.

6. Calon mahasiswa melakukan penyerahan berkas-berkas :

- FC bukti pembayaran registrasi

- FC Ijazah legalisir atau SKL dari sekolah 1 lembar

- FC SKHUN legalisir, atau FC SKHUN sementara legalisir 1 lembar

- FC Akte Kelahiran 1 Lembar

- FC Kartu Keluarga 1 Lembar

- Pas foto terbaru berwarna ukuran 3×4 dan 4×6 masing-masing 2 lembar

- FC nilai raport semester 2,3,4 legalisir (untuk jalur PMDK Raport dan SPSB)

- FC Sertifikat Kejuaraan legalisir (untuk jalur prestasi)

- Surat keterangan tidak mampu dari Desa (untuk jalur beasiswa)

7. Calon mahasiswa melakukan tes tulis akademik dan tes wawancara.

8. Calon mahasiswa menunggu pengumuman hasil seleksi.

9. Calon Mahasiswa melakukan pendaftaran ulang jika sudah lulus tes tulis dan tes wawancara.

\section{Hasil perhitungan dari rumus CFC}

Berdasarkan model proses bisnis tersebut, diperoleh rumus umum CFC adalah sebagai berikut:

$$
C F C(x)=\sum C F C_{X O R-s p l i t}(x)+\sum C F C_{O R-s p l i t}(x)+\sum C F C_{A N D-s p l i t}(x)
$$

dimana : $\sum C F C_{X O R-\text { split }}(x)=$ jumlah percabangan $(\mathrm{x})$

$$
\begin{aligned}
& \sum C F C_{O R \text {-split }}(x)=2^{\text {jumlah percabangan }(\mathrm{x})-1} \\
& \sum C F C_{A N D \text {-split }}(x)=1
\end{aligned}
$$

Maka, perhitungan dari model proses bisnis jalur A (luring) adalah,

$C F C(A)=\sum C F C_{X O R \text {-split }}(A)+\sum C F C_{O R-\text { split }}(A)+\sum C F C_{A N D \text {-split }}(A)$

$$
\begin{aligned}
& =13+2^{0-1}+1 \\
& =14,5
\end{aligned}
$$

Dan perhitungan model proses bisnis jalur B (daring) adalah,

$$
\begin{aligned}
C F C(B) & =\sum C F C_{X O R-\text { split }}(B)+\sum C F C_{O R-\text { split }}(B)+\sum C F C_{A N D-\text { split }}(B) \\
& =3+2^{0-1}+1 \\
& =4,5
\end{aligned}
$$


Dari perhitungan CFC, diperoleh model proses bisnis jalur A mempunyai kompleksitas 14,5 sedangkan model proses bisnis jalur B sebesar 4,5.

Kompleksitas proses bisnis di definisikan sebagai derajat tingkat kesulitan proses bisnis untuk dianalisa, dipahami dan dijelaskan. Kemudian mengusulkan Control Flow Complexity (CFC) sebagai matrik pengukuran derajat kompleksitas proses bisnis. Dalam hal ini proses bisnis telah dimodelkan dalam notasi pemodelan tertentu. Misalnya, BPMN (Business Process Modelling Notation), PNML (Petri Net Modelling Language) atau pemodelan lain. Disini, peneliti telah memodelkan proses bisnis dengan notasi PNML dan menghitung kompleksitas model proses bisnis dengan CFC. Pengukuran CFC didasarkan pada hipotesis bahwa perilaku control flow complexity pada proses bisnis dipengaruhi oleh split (perpecahan) dan join (gabungan). Namun, dalam mengukur CFC, perumusan formula untuk kompleksitas dititikberatkan pada pengaruh split yang ada pada model proses bisnis. Split yang umum dijumpai pada model proses bisnis adalah AND-split, XOR-split dan ORsplit.

Tabel 1. Tabel indikator komparasi

\begin{tabular}{|l|l|l|}
\hline Indikator komparasi & Model proses bisnis A & Model Proses bisnis B \\
\hline Xor-split & 13 & 3 \\
\hline Or-Split & $2^{0-1}$ & $2^{0-1}$ \\
\hline And-split & 1 & 1 \\
\hline Total CFC & $\mathbf{1 4 , 5}$ & $\mathbf{4 , 5}$ \\
\hline
\end{tabular}

Berdasarkan Tabel 1, indikator A (luring) lebih kompleks daripada model B (daring). Akan tetapi, model proses bisnis semestinya mudah dipahami dan mudah untuk di-maintain. Salah satu penyebab model proses bisnis menjadi tidak mudah dipahami adalah tingginya kompleksitas pada model proses bisnis tersebut. Kompleksitas yang tinggi merupakan kelemahan model proses bisnis yang rawan menyebabkan kesalahpahaman (bad understandability), cacat, serta kesalahan penafsiran proses bisnis sehingga biaya untuk mengembangkan dan menguji proses bisnis menjadi lebih mahal dan membutuhkan tambahan waktu. Langkah awal untuk mereduksi kompleksitas model proses bisnis adalah mengenali keberadaan elemen kompleksitas kemudian mengukur besarnya kompleksitas.

\section{KESIMPULAN}

Kesimpulan penelitian ini adalah pada perhitungan diperoleh model proses bisnis jalur A (luring) mempunyai kompleksitas sebesar 14,5 sedangkan model proses bisnis jalur B (daring) sebesar 4,5. Sehingga kompleksitas jalur luring lebih kompleks dari pada jalur daring. Akan tetapi, model proses bisnis semestinya mudah dipahami dan mudah untuk dimaintain. Sehingga model proses bisnis dengan tingkat kompleksitas lebih rendah akan lebih mudah dalam penerapannya. Berdasarkan penelitian ini, peneliti mengusulkan agar penerimaan mahasiswa baru di Universitas Nahdlatul Ulama Blitar menggunakan model proses Bisnis Penerimaan Mahasiswa Baru jalur daring karena kompleksitasnya lebih rendah sehingga mempermudah calon mahasiswa untuk melakukan proses pendaftaran.

\section{REFERENSI}

[1] M. Weske, Business process management: Concepts, languages, architectures. 2007.

[2] J. Cardoso, J. Mendling, G. Neumann, and H. A. Reijers, "A discourse on complexity of process models," Lect. Notes Comput. Sci. (including Subser. Lect. Notes Artif. Intell. Lect. Notes Bioinformatics), vol. 4103 LNCS, pp. 117-128, 2006.

[3] M. A. Yaqin, R. Sarno, and A. C. Fauzan, "Scalability measurement of business process model using business processes similarity and complexity," Int. Conf. Electr. Eng. Comput. Sci. Informatics, vol. 4, no. September, pp. 306-312, 2017. 
[4] J. Cardoso, "Evaluating the process control-flow complexity measure," Proc. - 2005 IEEE Int. Conf. Web Serv. ICWS 2005, vol. 2005, pp. 803-804, 2005.

[5] A. C. Fauzan, R. Sarno, and M. A. Yaqin, "Performance measurement based on coloured petri net simulation of scalable business processes," Int. Conf. Electr. Eng. Comput. Sci. Informatics, vol. 4, no. September, pp. 261-266, 2017.

[6] A. C. Fauzan, R. Sarno, M. A. Yaqin, and A. Jamal, "Extracting common fragment based on behavioral similarity using transition adjacency relations for scalable business processes," Proc. 11th Int. Conf. Inf. Commun. Technol. Syst. ICTS 2017, vol. 2018-Janua, pp. 131-136, 2018.

[7] A. C. Fauzan, R. Sarno, and M. A. Yaqin, "Petri net arithmetic models for scalable business processes," Proceeding - 2017 3rd Int. Conf. Sci. Inf. Technol. Theory Appl. IT Educ. Ind. Soc. Big Data Era, ICSITech 2017, vol. 2018-Janua, pp. 104-109, 2017. 